\title{
Expression profile of CREB knockdown in myeloid leukemia cells
} Matteo Pellegrini ${ }^{1}$, Jerry C Cheng
Julie Taylor ${ }^{2}$, Stanley F Nelson ${ }^{3}$ and Kathleen M Sakamoto ${ }^{4,5}$

Address: ${ }^{1}$ Department of Molecular, Cellular, and Developmental Biology, University of California, Los Angeles, USA, ${ }^{2}$ Division of Hematology-Oncology, Department of Pediatrics, Kaiser Permanente Medical Center, Los Angeles, USA, ${ }^{3}$ Department of Human Genetics, David Geffen School of Medicine at UCLA, Los Angeles, USA, ${ }^{4}$ Division of Hematology-Oncology, Department of Pediatrics, Gwynne Hazen Cherry Laboratories, Department of Pathology and Laboratory Medicine, David Geffen School of Medicine at UCLA, Los Angeles, USA and ${ }^{5}$ Division of Biology, California Institute of Technology, Pasadena, USA

E-mail: Matteo Pellegrini* - matteop@mcdb.ucla.edu; Jerry C Cheng - jerryccheng@gmail.com; Jon Voutila - jvoutila@ucla.edu; Dejah Judelson - dejahjudelson@ucla.edu; Julie Taylor - janntaylor@ucla.edu; Stanley F Nelson - snelson@ucla.edu; Kathleen M Sakamoto - kms@ucla.edu;

${ }^{*}$ Corresponding author

Published: 18 September 2008

BMC Cancer 2008, 8:264 doi: 10.1/86/147|-2407-8-264

This article is available from: http://www.biomedcentral.com/I47/-2407/8/264

This is an Open Access article distributed under the terms of the Creative Commons Attribution License (http://creativecommons.org/licenses/by/2.0), which permits unrestricted use, distribution, and reproduction in any medium, provided the original work is properly cited.

\begin{abstract}
Background: The cAMP Response Element Binding Protein, CREB, is a transcription factor that regulates cell proliferation, differentiation, and survival in several model systems, including neuronal and hematopoietic cells. We demonstrated that CREB is overexpressed in acute myeloid and leukemia cells compared to normal hematopoietic stem cells. CREB knockdown inhibits leukemic cell proliferation in vitro and in vivo, but does not affect long-term hematopoietic reconstitution.
\end{abstract}

Methods: To understand downstream pathways regulating CREB, we performed expression profiling with RNA from the K562 myeloid leukemia cell line transduced with CREB shRNA.

Results: By combining our expression data from CREB knockdown cells with prior ChIP data on CREB binding we were able to identify a list of putative CREB regulated genes. We performed extensive analyses on the top genes in this list as high confidence CREB targets. We found that this list is enriched for genes involved in cancer, and unexpectedly, highly enriched for histone genes. Furthermore, histone genes regulated by CREB were more likely to be specifically expressed in hematopoietic lineages. Decreased expression of specific histone genes was validated in $\mathrm{K} 562$, TF-I, and primary AML cells transduced with CREB shRNA.

Conclusion: We have identified a high confidence list of CREB targets in K562 cells. These genes allow us to begin to understand the mechanisms by which CREB contributes to acute leukemia. We speculate that regulation of histone genes may play an important role by possibly altering the regulation of DNA replication during the cell cycle.

\section{Background}

Several proto-oncogenes have been demonstrated to be deregulated in human cancer. In particular, the development of the hematologic malignancies such as leukemia, is associated with aberrant expression or function of proto-oncogenes such as c-myc, evi-1, and c-abl. Many translocations with cytogenetic abnormalities that characterize leukemias involve rearrangement of transcription factors, including AML-ETO and Nup98hox. Some of these leukemia-associated fusion proteins 
predict prognosis, e.g. $t(8,21), t(15,17)$, and inv(16) are associated with a good prognosis in acute myeloid leukemia (AML) [1]. Approximately 50\% of adult patients have been noted to have specific cytogenetic abnormalities. The overall survival of patients with AML is less than $50 \%$. Since half of the patients diagnosed with AML have normal cytogenetic profiles, it is critical to understand the molecular pathways leading to leukemogenesis.

We identified that the cyclic AMP Response Element Binding Protein (CREB) was overexpressed in the majority of bone marrow samples from patients with acute leukemia $[2,3]$. CREB is a leucine zipper transcription factor that is a member of the ATF/CREB family of proteins [4-6]. This transcription factor regulates proliferation, differentiation, and survival in a number of cell types, including neuronal and hematopoietic cells [4, 5]. CREB has been shown to be critical in memory and hippocampal development in mice $[7,8]$. We previously described that CREB is phosphorylated at serine 133 downstream of signaling by the hematopoietic growth factor, Granulocyte Macrophage-Colony Stimulating Factor (GM-CSF) in myeloid cells [9-11]. We further demonstrated that CREB phosphorylation results from the activation of the Mitogen Activated Protein Kinase (MAPK) and pp90 Ribosomal S6 Kinase (pp90RSK) pathways in response to GM-CSF stimulation [9].

To understand the role of CREB in normal and neoplastichematopoiesis we investigated the expression of CREB in primary cells from patients with acute lymphoblastic (ALL) and myeloid leukemia and found that CREB was overexpressed in the majority of leukemia cells from patients with ALL and AML at the protein and mRNA levels $[2,3,12]$. Furthermore, overexpression of CREB was associated with a worse prognosis. We created CREB transgenic mice that overexpressed CREB in myeloid cells. These mice developed enlarged spleens, high monocyte count, and preleukemia (myeloproliferative disease) after one year. Bone marrow progenitor cells from CREB transgenic mice had increased proliferative capacity and were hypersensitive to growth factors compared to normal hematopoietic stems cells (HSCs). Overexpression of CREB in myeloid leukemia cell lines resulted in increased proliferation, survival, and numbers of cells in S phase [12]. Known target genes of CREB include the cyclins A1 and D [4, 5, 12, 13]. Both of these genes were upregulated in CREB overexpressing cells from mice and human cell lines [4, 5]. Thus, CREB is a critical regulator of leukemic proliferation and survival, at least in part, through its downstream target genes.

CREB target genes have been published on the website developed by Marc Montminy http://natural.salk.edu/
CREB/ based on ChIP chip data [14]. Additional CREB target genes were described by Impey et al. [15]. In their studies, serial analysis of chromatin occupancy (SACO) was performed by combining chromatin immunoprecipitation (ChIP) with a modification of Serial Analysis of Gene Expression (SAGE). Using a SACO library derived from rat PC12 cells, approximately 41,000 genomic signature tags (GSTs) were identified that mapped to unique genomic loci. CREB binding was confirmed for all loci supported by multiple GSTs. Of the 6302 loci identified by multiple GSTs, $40 \%$ were within $2 \mathrm{~kb}$ of the transcriptional start of an annotated gene, 49\% were within $1 \mathrm{~kb}$ of a CpG island, and 72\% were within $1 \mathrm{~kb}$ of a putative cAMP-response element (CRE). A large fraction of the SACO loci delineated bidirectional promoters and novel antisense transcripts [15]. These studies suggest that CREB binds many promoters, but only a fraction of the associated genes are activated in any specific lineage. We therefore set out to measure the functional targets of CREB in a hematopoietic model system.

Since CREB is overexpressed in bone marrow cells from patients with acute leukemia compared to normal HSCs, this provides a potential target for leukemia therapy. To this end, we stably transduced myeloid leukemia cells with CREB shRNAlentivirus[16]. CREB knockdown by $80 \%$ resulted in decreased proliferation and differentiation of both normal myeloid cells and leukemia cells in vitro and in vivo [16]. However, downregulation of CREB did not affect short-term or long-term engraftment of normal HSCs in bone marrow transplantation assays [16]. To understand the pathways downstream of CREB, we investigated genes that were differentially regulated in CREB shRNA transduced cells. In this paper, we report expression profiling of genes that were differentially regulated in CREB knockdown K562 myeloid leukemia cells and could be potential targets for development of new therapies for acute leukemia.

\section{Methods \\ Cell lines}

The following human leukemia cell lines were transduced with shRNAs: K562 (Iscoves + 10\% FCS) and TF-1 (RPMI $+10 \%$ FCS + rhGM-CSF. Cells were cultured at $37^{\circ} \mathrm{C}, 5 \% \mathrm{CO} 2$ and split every 3 to 4 days. Primary AML bone marrow samples were processed as previously described [12]. All human samples were obtained with approval from the Institutional Review Board and consents were signed, according to the Helsinki protocol.

\section{shRNA sequence design and constructs}

The CREB specific shRNA sequences were selected and validated based on accepted parameters established by 
Tuschl et al. [17-19]http://www.rockefeller.edu/labheads/tuschl/sirna.html; CREB shRNA-1, CREB shRNA2, CREB shRNA-3. Controls included empty vector, luciferaseshRNA, and scrambled shRNA. shRNA sequences are: CREB shRNA-1(5'GCAAATGACAGTTCAAGCCC3'), shRNA-2 (5'GTACAGCTGGCTAACAATGG3'), shRNA-3 (5'GAGAGAGGTCCGTCTAATG3'), LuciferaseshRNA (5'GCCATTCTATCCTCTAGAGGA3'), Scramble shRNA (5'GGACGAACCTGCTGAGATAT3'). Short-hairpin sequences were synthesized as oligonucleotides and annealed according to standard protocol. Annealed shRNAs were then subcloned into pSICO-R shRNA vectors from the Jacks laboratory at MIT [20]. The second generation SIN vector HIV-CSCG was used to produce human shRNA vectors [21].

\section{Microarray analysis}

Total RNA $(10 \mu \mathrm{g})$ was extracted from K562 cells transduced with vector alone or CREB shRNA was submitted to the UCLA DNA Microarray Facility. RNA samples were labeled and hybridized by standard protocol to Affymetrix Gene Chip Human Genome U133+ Array Set HG-U133A array. Gene expression values were calculated using the MAS5 software. The expression values are quantile normalized across all arrays. We obtained the expression profiles for a control set and CREB downregulated K562 cells. A t-test is performed between the two groups to identify significantly differentially regulated genes. The analysis was performed using Matlab (Mathworks, Inc.). We find a significant number of differentially expressed genes, which are either direct or indirect targets of CREB.

To further characterize the data we have aligned CREB binding data from chromatin immunoprecipitation studies with our expression data. The chromatin immunoprecipitation data was obtained from the website http://natural.salk.edu/CREB/[14]. To identify genes that are most significantly bound by CREB and differentially expressed in our knockdown experiment we first filtered genes by their fold change (greater than 1.5 or less than 0.7 ). Finally, we ranked genes according to the product of the binding and expression P value (jerry_bind_data. xls) (see Additional file 1).

We characterize these genes using three types of analyses: Ingenuity Pathway Analysis (IPA), Gene Ontology term enrichment analysis and tissue distribution. For the former analysis, we used the Ingenuity Pathways Analysis tool on the lists of significant downregulated genes. We then identified functions that were overrepresented among these genes. For the second, we used the DAVID website http:// david.abcc.ncifcrf.gov/home.jsp to identify Gene Ontology terms that were enriched in the list.
Finally, we compute the tissue distribution of the 200 genes we identified as functional CREB targets. The tissue specific expression profiles of each gene are obtained from HG_U133A/GNF1H and GNF1M Tissue Atlas Datasets.[22]. We first compute the logarithm of the ratio of the expression intensity of each gene in each tissue, divided by its average intensity across all tissues. We then perform hierarchical clustering of both the genes and the tissues.

\section{Quantitative Real-time PCR}

K562 transduced with CREBshRNA $\left(5 \times 10^{6}\right)$ were lysed in Trizol and stored at $-80^{\circ} \mathrm{C}$ prior to RNA extraction. RNA extraction was performed according to a standard protocol supplied by the manufacturer (Invitrogen) and pellets were resuspended in RNAse free water. The cDNA was transcribed with a Superscript RT III based-protocol. DNAse treatment was not performed due to the selection of intron-spanning primers. Quantitative real-time PCR was performed with the SyberGreen reagent (Bio-Rad) in triplicates and analyzed by the standard curve method standardized to the housekeeping gene beta actin[23, 24].

\section{Results and discussion}

Since CREB has pleiotropic effects on cell function and potentially activates several genes in hematopoietic and leukemia cells, we performed microarray analysis with total RNA isolated from K562 chronic myeloid leukemia cells transduced with CREB or control shRNA. The comparison of transcriptional profiles in wild type and CREB shRNA transduced K562 cells revealed a large number of differentially expressed genes (see Additional file 2). Among these genes, some are direct targets of CREB, while others are indirect targets. To infer which of these genes was potentially directly regulated by CREB, we combined the expression data with the ChIP-chip data of CREB bound promoters as demonstrated by Marc Montminy[14]. As was previously observed CREB binding sites are highly conserved across different tissues. However, these sites are activated by CAMP in a tissues specific manner. Therefore by combining these two datasets we attempted to uncover the functional CREB sites in hematopoietic tissues.

Our hypothesis for discovering functional CREB sites in hematopoietic cells is that if a gene is found to be differentially expressed in the CREB shRNA K562 transduced cells, and bound by CREB it is likely to be a direct target. To identify these genes we developed a metric that accounts for both the significance of the expression change and binding data for each gene (described in detail in Methods). 
Since CREB has been described as both a transcriptional activator (when phosphorylated) and a repressor, we were interested in genes that were both up and downregulated in CREB shRNA transduced cells. The resulting rank ordered list allows us to sort genes by their likelihood of being functional CREB targets in K562 cells. It is difficult to determine, however, where to draw a threshold between the true and false targets. We have decided to restrict our analysis to the top several hundred targets that had both significant changes in expression and binding, as we deemed these to be highly enriched for true versus false targets. However, we do not claim that these are the only functional CREB targets in K562 cells, as the exact number of true targets is difficult to determine. The top down and upregulated genes revealed by this analysis are listed in Tables 1 and 2, and the full list is found in the supplementary materials.

Genes within the downregulated list were BECLIN 1, UBE2B. Both these genes have a cAMP responsive element binding site(s) in their promoters. These genes were selected for further validation because they are known to be involved in autophagy/apoptosis (BECLIN 1), cell cycle/ DNA repair (UBE2B) [25-28]. Quantitative real timepolymerase chain reaction (qRT-PCR) with mRNA from AML cell lines (K562 and TF-1) and primary leukemic blasts from a patient with M4-AML was performed. UBE2B expression was significantly reduced in CREB shRNA transduced TF-1 and K562 myeloid leukemia cells compared to controls (Figure 1, p < 0.05). BECLIN and UBE2B were downregulated in primary AML cells transduced with CREB shRNA (Figure 1, p < 0.05).

Having confirmed the validity of our microarray results in these two test cases we set out to characterize the function of the complete list of CREB target genes using two annotation schemes. The first utilizes the annotation contained in the Ingenuity Pathway Analysis software (IPA). This analysis showed that there is a significant enrichment for cell cycle $(\mathrm{P}<1 \mathrm{e}-3)$ and cancer $(\mathrm{P}<1 \mathrm{e}-3)$ genes. The full list of genes associated with cancer is shown in Table 3. Many of these genes regulate cell cycle, signaling, DNA repair, or metabolism, which are consistent with previously published results $[5,15]$. Furthermore, the role of CREB in the pathogenesis of leukemias has also been described in the literature $[2,3,12,29]$.

IPA also allows us to study CREB target genes in the context of protein-protein interactions networks. A network for downregulated genes interacting with CREB is shown in Figure 2, with a subset of the downregulated targets shown in grey, while other genes not in the target list that interact with these, shown in white. Here we see that there is prior literature supporting our analysis that CREB1 regulates PTGS2
(COX2), NR4A3 and TOM1, as depicted by the blue lines. Interestingly, COX2 is an important drug target, and suggests that commonly used COX2 inhibitors may provide a target for acute leukemia.

The second analysis that we performed used the terms from Gene Ontology to identify common characteristics among the top K562 CREB targets. Here we find the striking and unexpected result that ten percent of the downregulated targets code for histone genes $(\mathrm{P}<1 \mathrm{e}-10$, Table 4). We also performed an analysis of the top upregulated genes but did not find any significant GO terms. Although there is some prior literature indicating that CREB or CREB-related pathways may play a role in regulating histone modifications primarily through the histone acetylase CREB Binding Protein (CBP)[5, 30, $31]$, the fact that CREB directly regulates the transcription of histone genes in these cells is unexpected.

To further validate the hypothesis that CREB is an activator of these 20 histone genes, we utilized previously published analyses of the gene promoters to identify consensus CREB binding sequences. The results shown in Table 1 demonstrate that nearly all the histone genes contain CREB half sites along with a TATA box in the vicinity of these. Thus three lines of evidence support the assignment of these 20 histone genes as CREB targets in K562 cells: expression, binding and sequence based.

We examined the distribution of expression of these 20 histone genes across human tissues. The expression data were obtained from the GNF body atlas. We were able to extract expression profiles for 81 histone genes contained in the human genome. Fifteen of these overlapped with the 20 histone CREB targets. We show the expression of all 81 histone genes in Figure 3, where the identity of the 15 CREB target genes is shown in the last row. We see that the 15 genes are clustered into two groups containing more than one gene, with a third group consisting of a single histone HIST1H1C. One of the groups contains histones that are broadly expressed across human tissues, and particularly in all hematopoietic tissues. The second group is instead expressed in a very narrow range of tissues including $\mathrm{K} 562$ cells, bone marrow, prostate and thymus.

We examined the expression of three histones that are putative targets of CREB by real time PCR with mRNA from K562, TF-1, and primary cells from patients with AML. The three histones selected were based on our microarray analyses. Our results demonstrated a statistically significant decrease in histonesHIST1 $\mathrm{H} 2 \mathrm{Bj}$, HIST1H3B, and HIST2H2AA in K562 and TF-1 cells (Figure 4). Interestingly, in primary cells from a patient with AML, only HIST1H3B and HIST2H2AA, but not HIST1H2BJ expression was decreased with CREB 
Table I: Potential CREB target genes.

\begin{tabular}{|c|c|c|c|c|c|c|c|}
\hline Gene Name & Fold Change & CREB binding & CREB site & Gene Name & Fold Change & CREB binding & CREB site \\
\hline DKFZP434G222 & 0.551725 & 3.883395 & ht h & HSPC056 & 0.44548 & 1.892546 & ht h \\
\hline$A B C G 2$ & 0.479066 & 2.244422 & ht h & HSU79303 & 0.573524 & 1.812829 & ht \\
\hline ALDH2 & 0.5604 & 1.989872 & none & ILVBL & 0.675128 & 1.893295 & ht h \\
\hline ALDH7AI & 0.62012 & 2.051646 & $\mathrm{~h}$ & KIAA0I03 & 0.682528 & 2.620283 & ht h \\
\hline ALS2CRI9 & 0.46208 & $1.788 \mid 88$ & ht & HSU79303 & 0.573524 & 1.812829 & ht \\
\hline ANC_2HOI & 0.659044 & 1.991467 & ht $\mathrm{h}$ & ILVBL & 0.675128 & 1.893295 & ht h \\
\hline ANG & 0.693535 & 3.287977 & ht & KIAA0I03 & 0.682528 & 2.620283 & ht h \\
\hline APLP2 & 0.636685 & 1.219917 & $\mathrm{~h}$ & KIAA0I4I & 0.689536 & 3.479426 & $\mathrm{~h}$ \\
\hline APPL & 0.668234 & 1.391059 & $\mathrm{~h}$ & KIAA0408 & $0.59527 \mid$ & 3.603389 & none \\
\hline ARFDI & 0.524897 & 2.336962 & ht & KIAA0494 & 0.67838 & 5.420821 & $\mathrm{~F}$ \\
\hline BCL2LII & 0.589894 & 3.191337 & $\mathrm{H} \mathrm{h}$ & KLF5 & 0.553523 & 2.062499 & $\mathrm{H}$ \\
\hline BECNI & 0.600243 & 1.151217 & $\mathrm{Hh}$ & KNSL8 & 0.468603 & 7.854334 & $\mathrm{HT} \mathrm{ft}$ \\
\hline BMX & 0.315984 & 1.072006 & none & KPNA5 & 0.562667 & 2.859517 & none \\
\hline C20orfI33 & 0.635849 & 2.420642 & $\mathrm{~h}$ & LANCLI & 0.647544 & 1.020319 & none \\
\hline C6orf67 & 0.610619 & 2.665053 & $\mathrm{~h}$ & LOC5I668 & 0.500097 & 1.062053 & ht h \\
\hline CA2 & 0.592202 & 1.082939 & ht & LOC5I762 & 0.599397 & 3.307553 & ht $\mathrm{h}$ \\
\hline CALB2 & 0.671562 & I.894443 & $\mathrm{h}$ & LYPLA3 & 0.664078 & 2.379015 & $\mathrm{HT} h$ \\
\hline CCDC2 & 0.533032 & 1.529166 & none & MAF & 0.597194 & 2.383458 & FT \\
\hline CENPE & 0.306986 & 3.736367 & FT ht & MAPKAPK5 & 0.699356 & 2.053184 & $\mathrm{FH}$ \\
\hline CGI-77 & 0.664435 & 4.334985 & $\mathrm{H}$ ht h & MDM2 & 0.468991 & 2.523732 & none \\
\hline CLDNI8 & 0.566707 & 4.30699 & ht h & MGCI54I9 & 0.617252 & 3.032433 & $\mathrm{~h}$ \\
\hline CNNI & 0.670957 & I.I5022I & $\mathrm{F}$ ht $\mathrm{h}$ & MPHOSPHI & $0.42377 \mid$ & 3.535138 & ht h \\
\hline CREBI & 0.382751 & 1.816762 & HT H ht h & $\mathrm{MSH} 2$ & 0.592302 & 3.203985 & $\mathrm{~h}$ \\
\hline CSPG6 & 0.573523 & 3.082765 & $\mathrm{~h}$ & MVD & 0.632896 & 3.854905 & ht $\mathrm{h}$ \\
\hline CUL5 & 0.683117 & 2.073118 & $\mathrm{H}$ ht $\mathrm{h}$ & MYL4 & 0.69963 & 1.010099 & $\mathrm{~h}$ \\
\hline DBP & 0.67969 & 2.805267 & $\mathrm{ft}$ ht & NEFL & 0.343403 & 2.413823 & $\mathrm{HT} h$ \\
\hline DES & 0.521516 & I.509794 & ht $h$ & NFKBILI & 0.695019 & 4.072353 & ht \\
\hline DIS3 & 0.692573 & 3.837304 & HT ht & NIPSNAPI & 0.679129 & I.215594 & $\mathrm{h}$ \\
\hline DNCII & 0.673721 & 2.195167 & none & NOX3 & 0.455479 & 2.60292 & $\mathrm{~h}$ \\
\hline DNMT3A & 0.679821 & 1.035348 & $\mathrm{~h}$ & NR4A3 & 0.543361 & 5.002146 & $\mathrm{HT} \mathrm{H} \mathrm{h}$ \\
\hline DSIPI & 0.40458 & 2.546212 & HT & NUDT5 & 0.673003 & 2.561752 & $\mathrm{~h}$ \\
\hline DUSPI9 & 0.674195 & 2.225933 & none & NUMB & 0.675667 & 1.014954 & HT ht \\
\hline EIF2SI & 0.631867 & 1.075696 & $\mathrm{H}$ ht $\mathrm{h}$ & PDE6B & 0.66696 & 2.699363 & $\mathrm{~h}$ \\
\hline EIF2S2 & 0.644661 & 3.313634 & ht h & PEXI2 & 0.694707 & 6.199684 & $\mathrm{~h}$ \\
\hline ESRRBLI & 0.67914 & 4.633352 & $\mathrm{FH} \mathrm{h}$ & PFDN4 & 0.507631 & 2.196535 & none \\
\hline $\mathrm{FBXO} 22$ & 0.688756 & 2.206273 & ht & $\mathrm{PHCl}$ & 0.672187 & 1.053985 & HT \\
\hline $\mathrm{FECH}$ & 0.516446 & 1.045191 & $\mathrm{~h}$ & PKD2L2 & 0.513894 & 2.249593 & $\mathrm{~h}$ \\
\hline $\mathrm{FECH}$ & $0.65847 \mid$ & 1.045191 & $\mathrm{~h}$ & PLAA & 0.603854 & 9.235476 & none \\
\hline FLJ 10853 & 0.622952 & 3.981514 & $\mathrm{H}$ ht & PPPIR2 & 0.568734 & 2.04019 & $\mathrm{ft}$ \\
\hline FLJ 10858 & 0.668758 & 1.523113 & none & PRDX3 & 0.615229 & I.847784 & none \\
\hline FLJ 10904 & 0.54026 & $|.08534|$ & none & PSATI & 0.47554 & 2.492965 & ht \\
\hline FLJIIOII & 0.610253 & 3.387879 & ht $h$ & PSMAL/GCP & 0.68221 & 1.341117 & none \\
\hline FLJII 342 & 0.683482 & 2.617474 & ht & PTGS2 & $0.68440 \mathrm{I}$ & 3.057276 & ht $h$ \\
\hline FLJII7II2 & 0.62618 & 2.776373 & ht & RAB3I & 0.698664 & I.12667 & ht \\
\hline FLjI349| & 0.633125 & 3.268155 & none & $\mathrm{RBICCI}$ & 0.533475 & 1.390318 & none \\
\hline FLJ20I30 & 0.640787 & 2.766588 & $\mathrm{~h}$ & RFC3 & 0.577787 & 6.745001 & $\mathrm{FH}$ ht \\
\hline FLJ2033I & 0.681859 & 8.752576 & $\mathrm{H}$ & RHEB & 0.682202 & 3.47317 & $\mathrm{HT} \mathrm{H} \mathrm{h}$ \\
\hline FLJ20333 & 0.690542 & 1.946262 & ht $h$ & RNASE4 & 0.436168 & 2.975774 & ht $h$ \\
\hline FLJ20509 & 0.691949 & 1.96435 & none & SARS2 & 0.692149 & 5.455469 & $\mathrm{H} \mathrm{h}$ \\
\hline FLJ23233 & 0.471676 & 1.517415 & none & SBBI26 & 0.683312 & 6.75719 & $\mathrm{H}$ \\
\hline FOXDI & 0.593522 & 5.160553 & HT ht & SDP35 & 0.502432 & 2.320591 & $\mathrm{~h}$ \\
\hline GCAT & 0.656744 & 2.122675 & ht h & SERPINII & 0.31594 & 3.277692 & ht \\
\hline GCHFR & 0.676365 & 2.188753 & ht h & SHMTI & 0.658252 & I.127084 & ht h \\
\hline GFIIB & 0.671179 & 0.999255 & $\mathrm{~h}$ & SILV & 0.662805 & 2.130617 & $\mathrm{H}$ \\
\hline GMPR & 0.672975 & I.149663 & ht & SLCIIA2 & 0.684325 & 1.842417 & none \\
\hline GOLGA4 & 0.567882 & 2.939327 & ht $h$ & SLC22A5 & 0.657746 & 1.64513 & none \\
\hline GPNMB & 0.410992 & 1.004344 & none & SLC27A6 & 0.547039 & 1.029816 & ht \\
\hline GRHPR & 0.68706 & 2.454475 & $\mathrm{H}$ ht & SLC2A4 & 0.507466 & 2.273185 & ht h \\
\hline $\mathrm{H} 2 \mathrm{BFS}$ & 0.591569 & 2.358423 & ht & SLC39A8 & 0.201136 & 1.004832 & none \\
\hline HBEI & 0.639376 & $0.947 \mid 59$ & $\mathrm{~h}$ & SLC4A7 & 0.532067 & $|.26253|$ & ht \\
\hline HDGFRP3 & 0.65013 & I.208322 & none & SMARCAI & 0.519982 & 1.056916 & HT ht \\
\hline HDGFRP3 & 0.668211 & I.208322 & none & SMC2LI & 0.596288 & 2.916083 & ht h \\
\hline HEXA & 0.54467 & 2.622927 & none & SRI & 0.671893 & 0.826457 & ht \\
\hline HISTIHIC & 0.590374 & $1.9835 \mid 4$ & $\mathrm{~h}$ & STKI6 & 0.680797 & 6.555535 & $\mathrm{H} \mathrm{h}$ \\
\hline
\end{tabular}


Table I: Potential CREB target genes. (Continued)

\begin{tabular}{|c|c|c|c|c|c|c|c|}
\hline HISTIH2AD & 0.66909 & 4.768013 & ht $h$ & SULTIC2 & 0.599235 & 3.511947 & $f h$ \\
\hline HISTIH2AI & 0.542518 & 2.801688 & $\mathrm{H}$ ht $\mathrm{h}$ & SURB7 & 0.498245 & 1.598812 & ht \\
\hline HISTIH2AJ & 0.696531 & 3.066865 & $\mathrm{ft}$ ht $\mathrm{h}$ & SYNI & 0.696375 & 3.016534 & $\mathrm{~F} \mathrm{~h}$ \\
\hline HISTIH2AL & 0.602018 & 2.600144 & $\mathrm{FHT} h \mathrm{~h}$ & TAFIA & 0.589389 & 2.689618 & none \\
\hline HISTIH2BB & 0.590821 & 1.782458 & ht $h$ & TBCID7 & 0.692755 & 1.281463 & ht \\
\hline HISTIH2BD & 0.674855 & 3.111055 & $\mathrm{HT}$ ht h & TCTEIL & 0.368312 & $2.4756 \mathrm{II}$ & ht \\
\hline HISTIH2BE & 0.546621 & 2.34815 & ht & TFDP2 & 0.670657 & 1.016413 & ht \\
\hline HISTIH2BF & 0.543665 & 1.985466 & ht & TGDS & 0.67197 & I.5234 | | & none \\
\hline HISTIH2BH & 0.617917 & 2.04185 & none & THRB & 0.670555 & 2.256453 & $\mathrm{H}$ ht h \\
\hline HISTIH2BI & 0.585897 & 1.443622 & ht & TMEMI4A & 0.656093 & I.175355 & ht $h$ \\
\hline HISTIH2BJ & 0.493823 & 5.335159 & $\mathrm{HT}$ ht h & TOMI & 0.64031 & 3.221137 & $\mathrm{~h}$ \\
\hline HISTIH2BM & 0.687469 & 3.533372 & $\mathrm{ft}$ ht $\mathrm{h}$ & TXN2 & 0.689274 & 1.893339 & $\mathrm{H}$ ht h \\
\hline HISTIH2BO & 0.618862 & 4.014214 & ht $h$ & UBE2B & 0.663194 & 3.652863 & $\mathrm{H}$ ht $\mathrm{h}$ \\
\hline HISTIH3B & 0.556438 & 4.260113 & $\mathrm{ft}$ ht & VRKI & 0.650583 & 1.000406 & $\mathrm{~h}$ \\
\hline HISTIH3H & 0.641946 & 2.647758 & $\mathrm{H}$ ht $\mathrm{h}$ & WASPIP & 0.572355 & 1.01892 & none \\
\hline HISTIH4E & 0.608257 & 2.458831 & FT h & WDHDI & 0.624889 & 4.984045 & $\mathrm{H}$ ht $\mathrm{h}$ \\
\hline HISTIH4I & 0.612088 & 2.068983 & ht & WWox & 0.671866 & I.882778 & $\mathrm{h}$ \\
\hline HIST2H2AA & 0.560962 & 4.032876 & ht & ZNFI34 & $0.67748 \mid$ & 2.726853 & ht h \\
\hline HLA-DRA & $0.365|4|$ & 3.086303 & ht $h$ & ZNF222 & 0.5618 & 4.09755 & ht $h$ \\
\hline HLXB9 & 0.667926 & 1.006593 & none & ZNF230 & 0.410725 & 3.76825 & ht h \\
\hline HS2STI & 0.694429 & 1.032562 & ht $h$ & ZNF235 & $0.3837 \mid$ & 2.959812 & none \\
\hline HSBPI & 0.671929 & 1.891961 & ht $h$ & & & & \\
\hline
\end{tabular}

Top down-regulated genes that show significant CREB binding and changes in expression in the CREB knockdown cells. The detailed criteria for selecting these genes are described in the methods section. For each grouping of genes, from left to right, column I shows the gene symbols, column 2 the ratio of the expression change in wild type versus knockdown, column 3 the CREB binding ratio and column 4 the presence of CREB binding motifs. The key for column 4 is as follows: $F$ is a full CREB motif (TGACGCTA) that is conserved from human to mouse, while $f$ is not conserved, $H$ is a conserved CREB half motif (TGACG or CGTCA), while $h$ is not conserved, and $T$ is the conserved presence of a TATA motif less than 300 base pairs downstream of the CREB motif, while $t$ is not conserved.

Table 2: Potential CREB target genes.

\begin{tabular}{|c|c|c|c|c|c|c|c|}
\hline Gene Name & Fold Change & CREB binding & CREB site & Gene Name & Fold Change & CREB binding & CREB site \\
\hline ACOXI & 2.110674 & 2.911283 & $\mathrm{H}$ ht & LDLR & I.678587 & 1.525499 & ht \\
\hline ADATI & 1.410234 & 3.769574 & $h t f h$ & LGALS3BP & 2.131291 & 3.615437 & none \\
\hline APEH & I.40026I & 2.527266 & $\mathrm{~h}$ & LIM & 1.696177 & 1.097432 & none \\
\hline APPBP2 & 1.486616 & 2.151867 & $\mathrm{H}$ ht $\mathrm{h}$ & LIM & I.849989 & 1.097432 & none \\
\hline ARHB & 2.758453 & 2.77377 & $\mathrm{H}$ ht & LRRFIPI & 1.941595 & I. 122307 & $\mathrm{~h}$ \\
\hline ATP6VIA & $\mathrm{I} .446867$ & 3.016595 & HT ht h & METAP2 & 1.916632 & 2.635425 & ht \\
\hline BCL6 & 1.640646 & 6.084626 & HT ht & METTL2 & 1.593867 & 3.474639 & none \\
\hline BDKRB2 & 1.600927 & 2.601219 & none & MGC273I & I.588545 & $2.8008 \mathrm{I}$ & $\mathrm{HT} h$ \\
\hline BTN3A2 & 1.465264 & 3.426679 & ht & MGC4054 & 1.502743 & 2.777966 & ht \\
\hline C20orfl 2 & 1.511854 & 3.12999 & $\mathrm{~h}$ & MOCS3 & 1.796255 & 5.213295 & none \\
\hline C20orfl2I & 1.456022 & 3.532969 & $\mathrm{H}$ & MRPSIO & I.4I047| & 1.834794 & ht $f$ \\
\hline C20orfl 72 & 1.463616 & 4.659037 & $\mathrm{H} \mathrm{h}$ & NCOA3 & 1.495237 & 2.715807 & ht \\
\hline C20orf23 & 1.528396 & 2.622103 & none & NDRGI & 2.030896 & 2.312257 & ht h \\
\hline CD44 & 9.531947 & 1.335178 & ht $h$ & NEDF & 1.567662 & 4.268912 & $\mathrm{ft}$ ht \\
\hline CDHI2 & 3.296441 & I.178959 & none & NPR2L & 1.618864 & 6.397355 & ht $\mathrm{h}$ \\
\hline CDKALI & 1.735322 & 3.445022 & none & ODZI & 1.448279 & 2.310975 & ht \\
\hline CDKNIA & 2.216725 & I.778747 & $\mathrm{H}$ ht $\mathrm{h}$ & OPA3 & 1.474233 & $7.63 \mid 458$ & FHT ht h \\
\hline CELSR3 & 1.546375 & 3.175919 & $\mathrm{H}$ ht & ОTC & 1.693003 & $4.88 \mid 484$ & ht \\
\hline CENPF & 1.415064 & 2.654622 & ht & PAFAH2 & 1.67217 & 4.584628 & none \\
\hline CHRNBI & 1.55045 & 1.412576 & $\mathrm{H} \mathrm{h}$ & PAFAH2 & 1.631066 & 4.584628 & none \\
\hline CLECSF2 & I.747573 & 1.251667 & none & $\mathrm{PHC} 3$ & $1.4226 \mathrm{I}$ & $1.747 \mid 54$ & ht \\
\hline CML2 & 1.47905 & 3.427882 & ht & PHLDAI & 3.92008 & $2.00317 \mid$ & $\mathrm{h}$ \\
\hline COLI5AI & 2.56792 & I.394566 & none & PLAT & 1.668223 & 1.95203 & none \\
\hline CREM & I.793497 & 3.67068 & $\mathrm{H}$ & PLEKHB2 & 1.568395 & 4.611748 & $f$ \\
\hline CRKL & 1.690269 & 3.051845 & $\mathrm{H} \mathrm{h}$ & PPARGCI & 2.268458 & 2.972107 & $\mathrm{HT} F \mathrm{ht} h$ \\
\hline CSMDI & 1.647116 & 1.61907 & ht & PPFIBPI & 1.852526 & 2.550633 & ht h \\
\hline CTMP & I.548763 & 3.386235 & none & PPPIRIO & 1.870902 & 2.447557 & $\mathrm{H} \mathrm{h}$ \\
\hline DBT & 1.518604 & 4.292329 & none & PPPIR3B & 1.693114 & 1.622596 & $\mathrm{~h}$ \\
\hline DCLREIC & 1.41992 & 3.010944 & none & PSMAL/GCP & I.506527 & 2.707076 & none \\
\hline DDOST & 1.582101 & 2.508459 & ht & RAB7LI & 1.638378 & 1.15364 & ht $h$ \\
\hline
\end{tabular}


Table 2: Potential CREB target genes. (Continued)

\begin{tabular}{|c|c|c|c|c|c|c|c|}
\hline $\mathrm{DD} \times 3 \times$ & 1.817009 & 3.42975 & none & RABL2B & 1.486054 & 2.496157 & $\mathrm{~h}$ \\
\hline DEGS & $|.48822|$ & I.464348 & none & RASSFI & $|.43| 27 \mid$ & 4.04395 & none \\
\hline DIAPHI & 1.412484 & 2.96506 & none & RBLI & I.529652 & 2.451247 & $\mathrm{~h}$ \\
\hline DUSPI & I.578824 & 2. 102797 & FT HT ht h & REL & 1.944847 & I.I43935 & $\mathrm{H} \mathrm{h}$ \\
\hline EGR2 & 5.148023 & 2.036633 & $\mathrm{HT}$ ht $\mathrm{h}$ & RHOBTB3 & 1.63057 & 2.813465 & none \\
\hline EIF5 & I.422558 & 4.208549 & ht h & RIOK3 & I.4095| & 2.008376 & none \\
\hline ELKI & $|.405| 7 \mid$ & 4.088789 & ht & RNASE6PL & 1.561704 & 2.252099 & ht \\
\hline $\mathrm{ENCl}$ & $|.957| 5 \mid$ & I.549567 & $\mathrm{h}$ & RNF32 & 1.954396 & 1.603905 & $\mathrm{H}$ ht \\
\hline F2R & I.804785 & 1.098488 & ht $h$ & SAS & 1.768493 & 7.735178 & HT ht h \\
\hline FAMI3AI & I.780869 & 2.014276 & none & SERPINB9 & 2.244605 & 1.418097 & ht $h$ \\
\hline FAT & $2.0005 \mathrm{I}$ & 1.816506 & $\mathrm{~F} \mathrm{ht}$ & SFPQ & I.477265 & 3.428149 & ht \\
\hline FKBPI4 & 1.78994 & 3.042488 & ht & SHARP & 1.558516 & $1.078 \mid 88$ & $\mathrm{H}$ ht \\
\hline FLJI 078I & I.463332 & I.II3364 & ht $h$ & SLC3IAI & 1.491104 & 3.803168 & $\mathrm{FH}$ ht \\
\hline FLJ 10803 & 1.726196 & 2.63943 & ht & SLC35E3 & 1.716026 & 1.969928 & ht \\
\hline FLJIII 029 & $|.42200|$ & 3.085667 & ht $\mathrm{h}$ & SLC38A2 & I.4977I6 & 1.914154 & $\mathrm{H}$ ht \\
\hline FLJIIIISI & 2.413055 & I.840398 & $\mathrm{h}$ & SLC39A6 & I.477678 & 3.119807 & $\mathrm{~h}$ \\
\hline FLJ20507 & 1.730068 & 2.92287 I & $\mathrm{H}$ ht $\mathrm{h}$ & SMA3 & I.414595 & 2.654203 & ht \\
\hline FOSLI & 2.220086 & 1.929543 & $\mathrm{HT}$ ht h & SMARCFI & I.537978 & 1.046929 & none \\
\hline FRSB & I.423607 & 2.982919 & ht & SNAP29 & $|.52| 48 \mid$ & 2.454502 & $\mathrm{~h}$ \\
\hline $\mathrm{FXCl}$ & 1.423019 & 5.02095 & HT H ht & SON & I.42477 & 4.933417 & $\mathrm{H}$ \\
\hline GALNS & $|.77233|$ & 2.592543 & $\mathrm{~h}$ & SPG4 & 1.413533 & 3.160161 & none \\
\hline GCA & $\mid .690161$ & $2.9280 \mathrm{I}$ & $\mathrm{H} \mathrm{h}$ & SUFU & 1.661693 & 2.275704 & ht $h$ \\
\hline GTF2H3 & I.59342। & 10.587057 & $\mathrm{H}$ & TAPI & 1.435113 & 3.105625 & $\mathrm{H} \mathrm{h}$ \\
\hline GYSI & 1.418699 & $2.559 \mid 54$ & $\mathrm{~h}$ & TIGD6 & 1.772719 & 3.636168 & $\mathrm{~h}$ \\
\hline HBSIL & I.475369 & 3.891767 & ht & TIMPI & 1.791155 & I.848I54 & $\mathrm{HT} h$ \\
\hline HIPI & $|.5372| 4$ & 2.114631 & ht $\mathrm{h}$ & TNFRSF2I & I.498482 & 2.635088 & ht \\
\hline HLA-C & I.429002 & 3.2916 & $\mathrm{~h}$ & TP53API & I.527339 & 3.493111 & ht h \\
\hline HSPG2 & $|.70836|$ & 1.453039 & none & TPM4 & 2.201468 & 1.33368 & $\mathrm{H}$ ht \\
\hline ICAMI & 2.20462 & I.198603 & ht $\mathrm{h}$ & TRIM26 & I.400065 & 6.12308 & ht \\
\hline IDI & I.521685 & 2.3068 & FT ht & TSSC3 & |.87928| & 2.01021 & $\mathrm{H}$ ht $\mathrm{h}$ \\
\hline IDS & I.508286 & 1.1848 & $\mathrm{~h}$ & TTFI & 1.513382 & 3.461645 & ht $h$ \\
\hline IER5 & 1.66867 & 2.847755 & $\mathrm{HT}$ ht & TUBA3 & 1.481437 & 2.500545 & none \\
\hline ILIORA & 1.64246 & 2.830231 & $\mathrm{f}$ & U2AFILI & 2.758542 & 3.548509 & ht \\
\hline ILIORB & 1.410005 & I.192048 & ht $\mathrm{h}$ & U5-II6KD & 2.223148 & 2.779884 & $\mathrm{~h}$ \\
\hline ILIRI & I.8I2093 & I.329947 & ht & USP2 & 2.35423 & 3.920336 & $\mathrm{HT} \mathrm{H} \mathrm{h}$ \\
\hline IL6 & 1.980266 & 1.460112 & $\mathrm{HT}$ ht & VPS4B & I.474465 & $6.69387 \mid$ & $\mathrm{H}$ ht \\
\hline IL6ST & 1.54702 & 3.418269 & none & YMEILI & 1.441837 & 1.843132 & $\mathrm{~F}$ ht h \\
\hline INPPI & $2.07 \mid 508$ & I.550। 35 & ht $h$ & ZFP37 & I.572207 & 4.659572 & ht $h$ \\
\hline ITGA5 & 2.028008 & $|.31513|$ & none & ZNFI42 & $1.509 \mid 4$ & 3.028386 & $\mathrm{~h}$ \\
\hline JM4 & 1.606813 & 2.392743 & $\mathrm{HT} h$ & ZNFI55 & 1.69746 & 4.195939 & none \\
\hline KIAA0266 & 1.504796 & $2.986 \mid 55$ & none & ZNFI89 & I.625836 & 4.104303 & ht h \\
\hline KIFI4 & I.453888 & 4.181899 & none & ZNF22I & $1.777 \mid 22$ & 3.569536 & none \\
\hline KIF3B & 1.623133 & I.560467 & none & ZNF324 & I.48860 I & 4.205703 & $\mathrm{~h}$ \\
\hline LCMT2 & $|.58722|$ & 2.338943 & $\mathrm{H}$ ht $\mathrm{h}$ & & & & \\
\hline
\end{tabular}

Top up-regulated genes that show significant CREB binding and changes in expression in the CREB knockdown cells. The detailed criteria for selecting these genes are described in the methods section. The column descriptions are the same as in Table I.

knockdown. These results suggest that histones are differentially expressed in AML and that specific histones are potential targets of CREB. This analysis supports the hypothesis that CREB regulates a subset of histone genes that are normally expressed in a small set of rapidly dividing tissues. These genes are presumably aberrantly activated in $\mathrm{K5} 62$ and other leukemia cells, and could potentially contribute to the malignant phenotype.

\section{Conclusion}

We have identified a high confidence list of CREB target genes in K562 myeloid leukemia cells. Several important CREB target genes that function in DNA repair, signaling, oncogenesis, and autophagy were identified. These genes provide potential mechanisms by which CREB contributes to the pathogenesis of acute leukemia. Expression of the genes beclin-1 and ube2b was found to be decreased in myeloid leukemia cell lines and primary AML cells in which CREB was downregulated. In addition, we speculate that CREB may have more global effects on transcription, primarily through the regulation of histone genes thereby altering the regulation of DNA replication during the cell cycle.

\section{Competing interests}

The authors declare that they have no competing interests. 
A

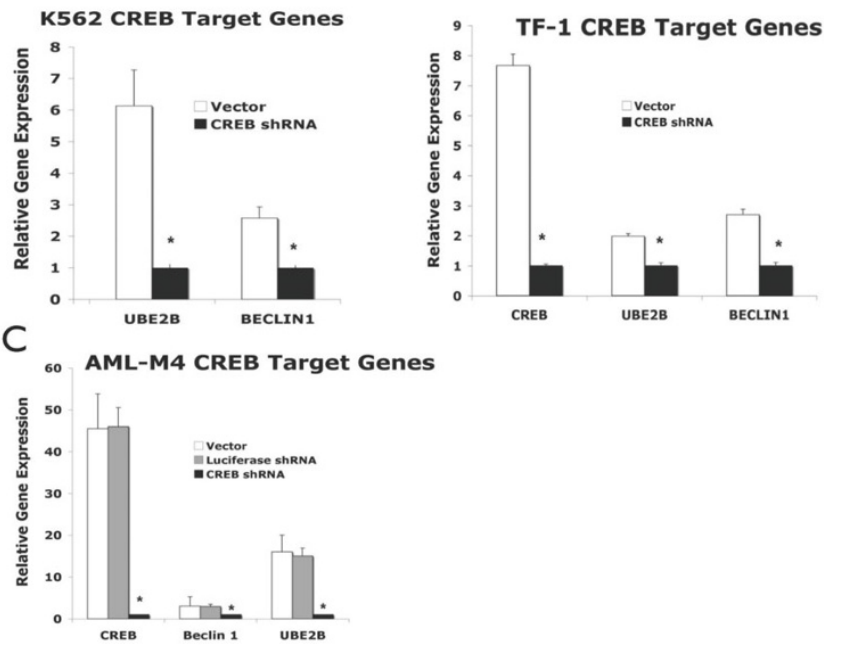

Figure I

Expression of potential target genes downstream of CREB in myeloid leukemia cells. Primers specific for the UBE2B, BECLINI, and CREB genes were generated and utilized for quantitative real-time PCR by SyberGreen method (Bio-Rad Inc.) Relative gene expression normalized to the housekeeping gene actin is shown for the following transduced cells: (A) K562

myeloid leukemia cells, (B) TF-I myeloid leukemia cells, and (C) Human AML-M4 blasts.

\section{Authors' contributions}

MP and SFN analyzed the microarray data, performed the statistical analysis, and drafted the manuscript. JCC, JC, DJ, and JT performed the real-time PCR experiments. KMS supervised the experiments and wrote the manuscript. All authors read and approved the final manuscript.

\section{Additional material}

\section{Additional File 1}

Supplementary table 1

Click here for file

[http://www.biomedcentral.com/content/supplementary/14712407-8-264-S1.xls]

\section{Additional File 2}

Supplementary table 2

Click here for file

[http://www.biomedcentral.com/content/supplementary/14712407-8-264-S2.txt]

\section{Acknowledgements}

We would like to thank Nori Kasahara and the Core Vector Laboratory for assistance with the CREB shRNA lentivirus. This work was supported by National Institutes of Health grants HL75826 (K.M.S.), HL83077 (K.M.S.), F32HL0850I 3 (J.C.), American Cancer Society grant RSG-99-08I-0I-LIB (K.M.S.), and Department of Defense grant CM050077 (K.M.S.). Microarray experimentation was supported by the UCLA NHLBI Shared Microarray Resource grant ROIHL72367 (S.F.N.). K.M.S. is a scholar of the Leukemia and Lymphoma Society.

Table 3: The subset of CREB target genes associated with cancer according to Ingenuity Pathways Analysis.

\begin{tabular}{|c|c|c|c|}
\hline Name & Location & Type & Drugs \\
\hline \multicolumn{4}{|c|}{ Downregulated Cancer Genes } \\
\hline $\mathrm{ABCG} 2$ & Plasma Membrane & transporter & \\
\hline ANG & Extracellular Space & enzyme & \\
\hline BCL2LII & Cytoplasm & other & \\
\hline BECNI & Cytoplasm & other & \\
\hline $\mathrm{BMX}$ & Cytoplasm & kinase & \\
\hline CA2 & Cytoplasm & enzyme & $\begin{array}{l}\text { methazolamide, hydrochlorothia- } \\
\text { zide, acetazolamide, } \\
\text { trichloromethiazide, dorzolamide, } \\
\text { chlorothiazide, dorzolamide/ } \\
\text { timolol, brinzolamide, } \\
\text { chlorthalidone, benzthiazide, } \\
\text { sulfacetamide, topiramate }\end{array}$ \\
\hline CENPE & Nucleus & other & \\
\hline CNNI & Cytoplasm & other & \\
\hline CREBI & Nucleus & transcription regulator & \\
\hline CUL5 & Nucleus & ion channel & \\
\hline GFIIB & Nucleus & transcription regulator & \\
\hline KLF5 & Nucleus & transcription regulator & \\
\hline MDM2 (includes EG:4193) & Nucleus & transcription regulator & \\
\hline MPHOSPHI & Nucleus & enzyme & \\
\hline $\mathrm{MSH} 2$ & Nucleus & enzyme & \\
\hline MVD & Cytoplasm & enzyme & \\
\hline NR4A3 & Nucleus & ligand-dependent nuclear receptor & \\
\hline NUMB & Plasma Membrane & other & \\
\hline PPPIR2 & Cytoplasm & phosphatase & \\
\hline
\end{tabular}


Table 3: The subset of CREB target genes associated with cancer according to Ingenuity Pathways Analysis. (Continued)

\begin{tabular}{|c|c|c|c|}
\hline PTGS2 & Cytoplasm & enzyme & $\begin{array}{l}\text { acetaminophen/pentazocine, aceta- } \\
\text { minophen/clemastine/pseudoephe- } \\
\text { drine, aspirin/butalbital/caffeine, }\end{array}$ \\
\hline $\mathrm{RBICCI}$ & Nucleus & other & \\
\hline SILV & Plasma Membrane & enzyme & \\
\hline SMC2 & Nucleus & transporter & \\
\hline SMC3 & Nucleus & other & \\
\hline TFDP2 & Nucleus & transcription regulator & \\
\hline THRB & Nucleus & ligand-dependent nuclear receptor & $\begin{array}{l}\text { 3,5-diiodothyropropionic acid, } \\
\text { amiodarone, thyroxine, L-triio- } \\
\text { dothyronine }\end{array}$ \\
\hline UBE2B & Cytoplasm & enzyme & \\
\hline VRKI & Nucleus & kinase & \\
\hline WWOX & Cytoplasm & enzyme & \\
\hline \multicolumn{4}{|l|}{ Upregulated cancer Genes } \\
\hline ACOXI & Cytoplasm & enzyme & \\
\hline ARIDIA & Nucleus & transcription regulator & \\
\hline BCL6 & Nucleus & transcription regulator & \\
\hline BDKRB2 & Plasma Membrane & G-protein coupled receptor & anatibant, icatibant \\
\hline CD44 & Plasma Membrane & other & \\
\hline CDKNIA & Nucleus & kinase & \\
\hline COLI5AI & Extracellular Space & other & collagenase \\
\hline CREM & Nucleus & transcription regulator & \\
\hline CRKL & Cytoplasm & kinase & \\
\hline DCLREIC & Nucleus & enzyme & \\
\hline DEGSI & Plasma Membrane & enzyme & \\
\hline DIAPHI & Cytoplasm & other & \\
\hline DUSPI & Nucleus & phosphatase & \\
\hline EGR2 & Nucleus & transcription regulator & \\
\hline ELKI & Nucleus & transcription regulator & \\
\hline $\mathrm{ENCl}$ & Nucleus & peptidase & \\
\hline $\mathrm{F} 2 \mathrm{R}$ & Plasma Membrane & G-protein coupled receptor & chrysalin, argatroban, bivalirudin \\
\hline FOSLI & Nucleus & transcription regulator & \\
\hline HIPI & Cytoplasm & other & \\
\hline HSPG2 (includes EG:3339) & Plasma Membrane & other & \\
\hline ICAMI & Plasma Membrane & transmembrane receptor & \\
\hline IDI & Nucleus & transcription regulator & \\
\hline IL6 & Extracellular Space & cytokine & tocilizumab \\
\hline ILIRI & Plasma Membrane & transmembrane receptor & anakinra \\
\hline IL6ST & Plasma Membrane & transmembrane receptor & \\
\hline ITGA5 & Plasma Membrane & other & \\
\hline KIFI4 & Cytoplasm & other & \\
\hline METAP2 & Cytoplasm & peptidase & PPI-2458 \\
\hline NCOA3 & Nucleus & transcription regulator & \\
\hline NDRG I & Nucleus & kinase & \\
\hline PHLDAI & Cytoplasm & other & \\
\hline PLAT & Extracellular Space & peptidase & \\
\hline RASSFI & Nucleus & other & \\
\hline RBLI & Nucleus & other & \\
\hline REL & Nucleus & transcription regulator & \\
\hline RHOB & Cytoplasm & enzyme & \\
\hline SERPINB9 & Cytoplasm & other & \\
\hline SUFU & Nucleus & transcription regulator & \\
\hline TIMPI & Extracellular Space & other & \\
\hline TNFRSF2I & Plasma Membrane & other & \\
\hline USP2 & Cytoplasm & peptidase & \\
\hline
\end{tabular}

Column $\mathrm{I}$ is the gene name, column 2 the localization, column 3 is a description of the protein function and column 4 are compounds that target the protein. 


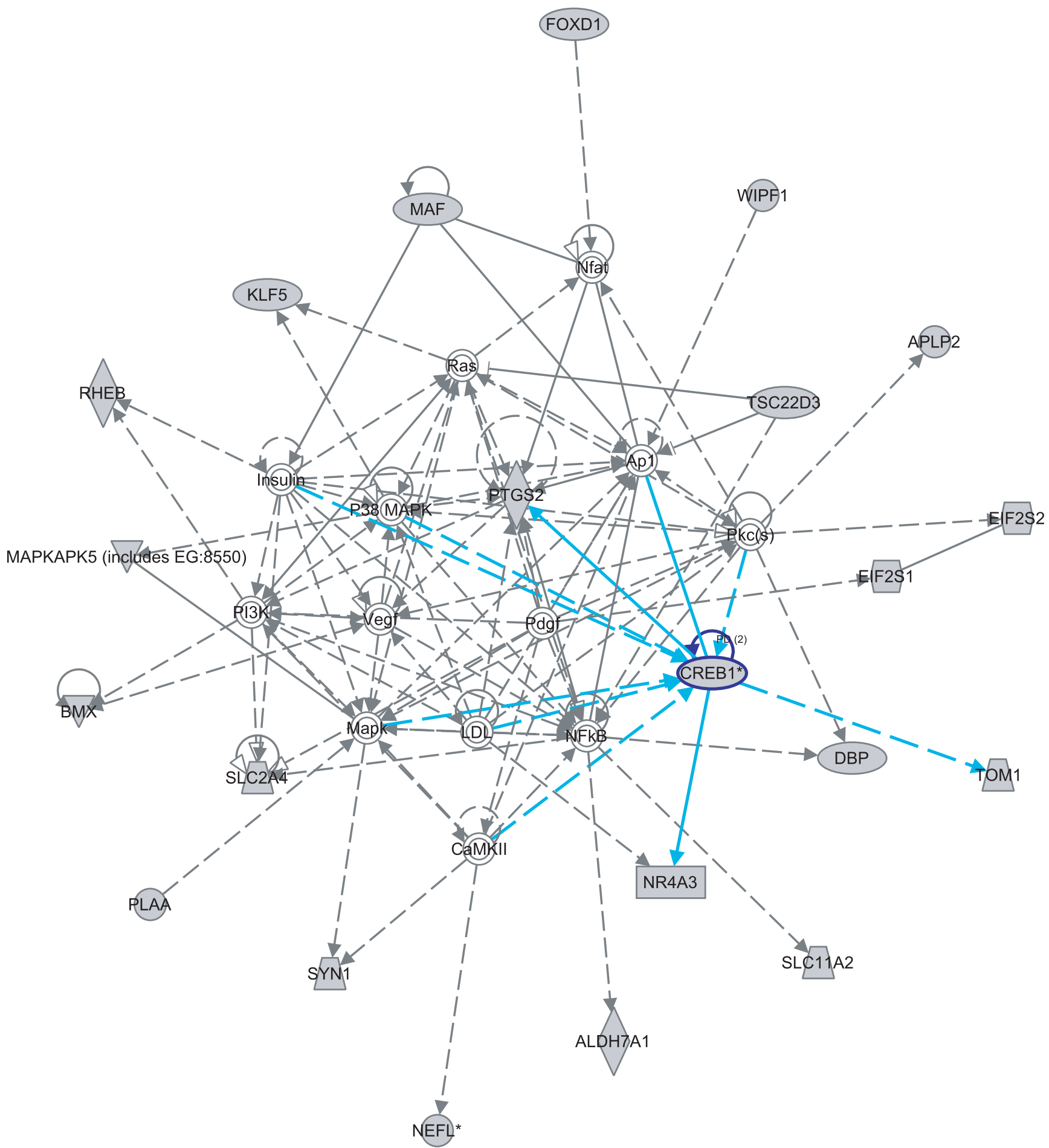

Figure 2

A network depicting interactions between direct CREB targets (shown in grey) and proteins that these interact with (shown in white). PTGS2, NR4A3 and TOMI are direct CREB targets whose regulation by CREB was previously described in the literature (clue lines). PTGS2 (COX2) emerges as a central player in this network, and is thus implicated as a potential regulator of leukemias. 
Table 4: Gene Ontology terms that are enriched among the top CREB targets.

\begin{tabular}{|c|c|c|c|c|}
\hline Category & Term & Count & $\%$ & PValue \\
\hline GOTERM_CC_ALL & nucleosome & II & $6.88 \%$ & $6.22 \mathrm{E}-10$ \\
\hline GOTERM_CC_ALL & chromosome & 17 & $10.62 \%$ & $2.39 \mathrm{E}-09$ \\
\hline GOTERM_BP_ALL & nucleosome assembly & 11 & $6.88 \%$ & $6.60 \mathrm{E}-09$ \\
\hline GOTERM_CC_ALL & chromatin & 13 & $8.12 \%$ & $7.56 \mathrm{E}-09$ \\
\hline GOTERM_BP_ALL & chromatin assembly & II & $6.88 \%$ & $1.66 \mathrm{E}-08$ \\
\hline GOTERM_BP_ALL & protein complex assembly & 15 & $9.38 \%$ & 2.19E-07 \\
\hline GOTERM_BP_ALL & chromatin assembly or disassembly & II & $6.88 \%$ & 3.84E-07 \\
\hline GOTERM_BP_ALL & chromosome organization and biogenesis & 15 & $9.38 \%$ & $5.56 \mathrm{E}-07$ \\
\hline GOTERM_BP_ALL & chromosome organization and biogenesis (sensu Eukaryota) & 14 & $8.75 \%$ & $1.63 \mathrm{E}-06$ \\
\hline GOTERM_CC_ALL & membrane-bound organelle & 75 & $46.88 \%$ & $1.93 \mathrm{E}-06$ \\
\hline GOTERM_CC_ALL & intracellular membrane-bound organelle & 74 & $46.25 \%$ & $4.63 \mathrm{E}-06$ \\
\hline GOTERM_CC_ALL & organelle & 83 & $51.88 \%$ & 5.39E-06 \\
\hline GOTERM_MF_ALL & DNA binding & 38 & $23.75 \%$ & 6.17E-06 \\
\hline GOTERM_BP_ALL & cellular physiological process & 118 & $73.75 \%$ & 8.86E-06 \\
\hline GOTERM_BP_ALL & establishment and/or maintenance of chromatin architecture & 12 & $7.50 \%$ & I.02E-05 \\
\hline GOTERM_CC_ALL & intracellular organelle & 82 & $51.25 \%$ & $1.28 \mathrm{E}-05$ \\
\hline GOTERM_BP_ALL & DNA packaging & 12 & $7.50 \%$ & I.38E-05 \\
\hline GOTERM_BP_ALL & organelle organization and biogenesis & 22 & $13.75 \%$ & I.59E-05 \\
\hline GOTERM_CC_ALL & nucleus & 56 & $35.00 \%$ & $2.46 \mathrm{E}-05$ \\
\hline GOTERM_BP_ALL & DNA metabolism & 19 & $11.88 \%$ & $2.63 \mathrm{E}-05$ \\
\hline
\end{tabular}

Column $\mathrm{I}$ is the ontology used (BP is biological process, CC is cellular localization and MF is molecular function), column 2 is the term, column 3 is the number of genes in the target list associated wit the term, column 4 is the percentage of genes in the target list associated with the term and column 5 is the $P$ value for observing this number genes associated with the term.

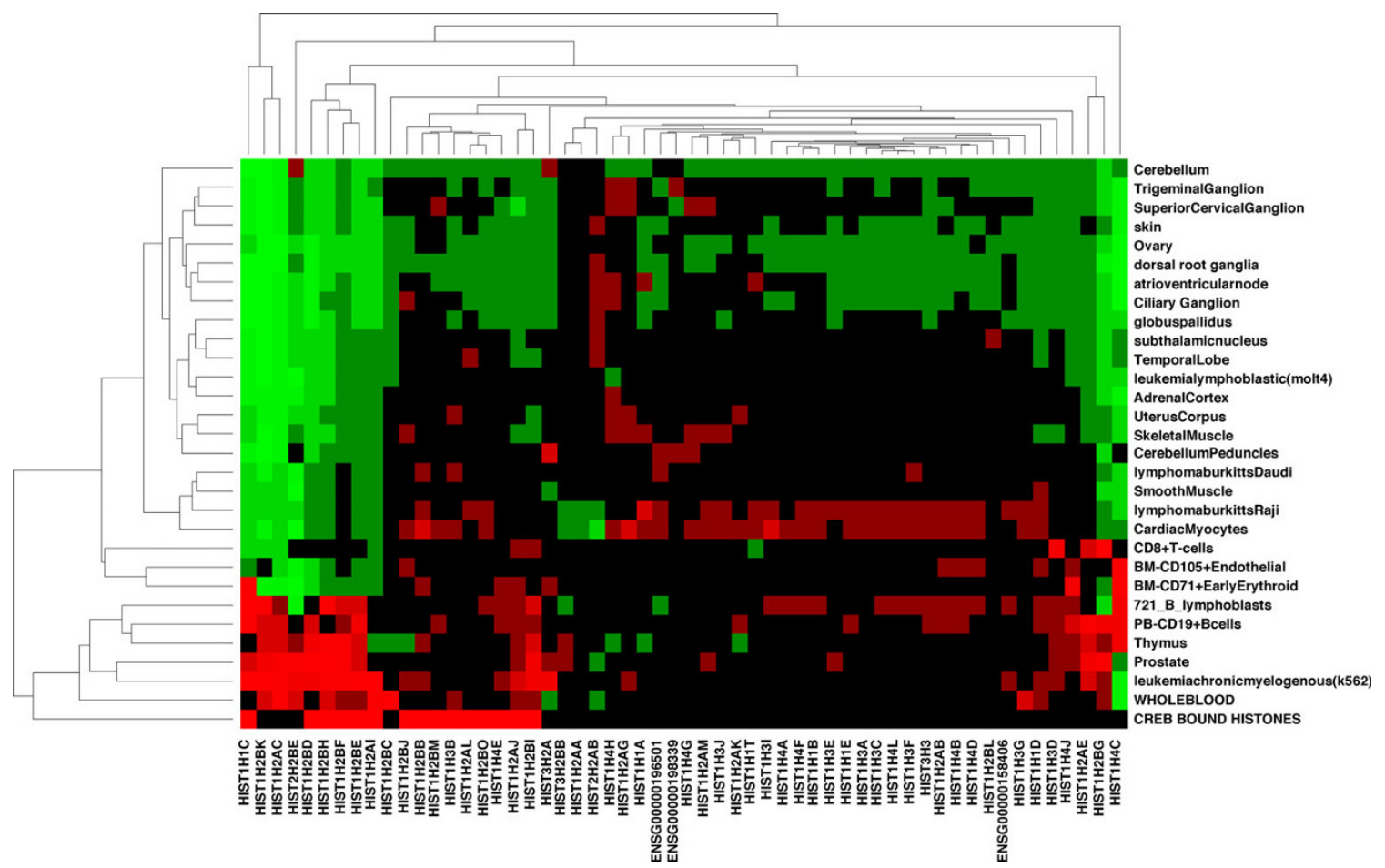

Figure 3

The tissue specific expression of histone genes. Each row of the figure represents a tissue from the GNF Body Atlas (see methods). We show only the top 30 tissues with highest variance of expression of histone genes. Each column represents a histone gene. We use hierarchical clustering to order the rows and columns according to their similarity. Red indicates that the gene is over expressed relative to its mean expression levels across all tissues, and green that it is under expressed. The histone genes that we identify as direct targets of CREB are shown in red in the last row of the figure. We see that many of these are only expressed in a small subset of rapidly dividing tissues along with K562 cells. 

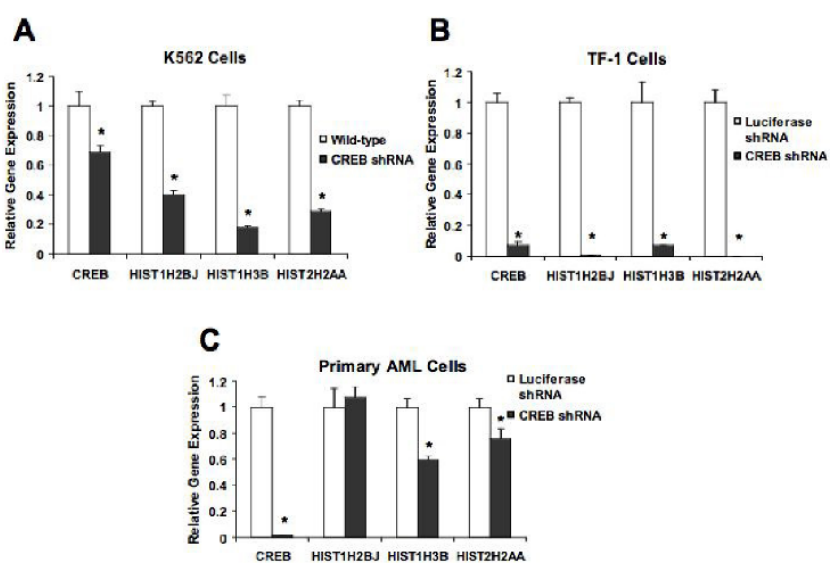

Figure 4

Expression of target histone genes is decreased in CREB knockdown myeloid leukemia cells. Primers specific for HISTIH2BJ, HISTIH3B, and HIST2H2AA were generated and utilized for quantitative real-time PCR by the SYBR Green method (Applied Biosystems). Relative gene expression normalized to the housekeeping gene actin is shown for the following transduced cells: (A) K562 myeloid leukemia cells, (B) TF-I myeloid leukemia cells, and (C) primary AML cells.

\section{References}

I. Woods WG: Curing childhood acute myeloid leukemia (AML) at the half-way point: promises to keep and miles to go before we sleep. Pediatr Blood Cancer 2006, 46(5):565-569.

2. Crans-Vargas H, Landaw E, Bhatia S, Sandusky G and Sakamoto K: CREB Expression in acute leukemias. Blood 2002, 99:2617-2619.

3. Crans-Vargas HN, Landaw EM, Bhatia S, Sandusky G, Moore TB and Sakamoto KM: Expression of cyclic adenosine monophosphate response-element binding protein in acute leukemia. Blood 2002, 99(7):2617-2619.

4. Haywitz $A$ and Greenberg M: CREB: a stimulus-induced transcription factor activated by a diverse array of extracellular signals. Annual Review of Biochemistry 1999, 68:82|-86I.

5. Mayr $B$ and Montminy $M$ : Transcriptional regulation by the phosphorylation-dependent factor CREB. Nat Rev Mol Cell Biol 200I, 2(8):599-609.

6. Shankar DB, Cheng JC and Sakamoto KM: Role of cyclic AMP response element binding protein in human leukemias. Cancer 2005, I04(9): 1819-1824.

7. Bito $H$, Deisseroth $\mathrm{K}$ and Tsien RW: CREB phosphorylation and dephosphorylation: a $\mathbf{C a}(2+)$ - and stimulus duration-dependent switch for hippocampal gene expression. Cell 1996, 87 (7): $1203-12 \mid 4$

8. Deisseroth K, Bito $H$ and Tsien RW: Signaling from synapse to nucleus: postsynaptic CREB phosphorylation during multiple forms of hippocampal synaptic plasticity. Neuron 1996, 16 (I):89-10I.

9. Kwon EM, Raines MA, Blenis J and Sakamoto KM: Granulocytemacrophage colony-stimulating factor stimulation results in phosphorylation of cAMP response element-binding protein through activation of pp90RSK. Blood 2000, 95(8):2552-2558.

10. Sakamoto KM, Fraser JK, Lee HJ, Lehman E and Gasson JC: Granulocyte-macrophage colony-stimulating factor and interleukin-3 signaling pathways converge on the CREBbinding site in the human egr-I promoter. Mol Cell Biol 1994 | 4(9):5975-5985.

II. Wong A and Sakamoto KM: Granulocyte-macrophage colonystimulating factor induces the transcriptional activation of egr-I through a protein kinase A-independent signaling pathway. I Biol Chem 1995, 270(5 I):3027I-30273.

12. Shankar DB, Cheng JC, Kinjo K, Federman N, Moore TB, Gill A, Rao NP, Landaw EM and Sakamoto KM: The role of CREB as a proto-oncogene in hematopoiesis and in acute myeloid leukemia. Cancer Cell 2005, 7(4):35I-362.

13. Scheid MP and Duronio V: Dissociation of cytokine-induced phosphorylation of Bad and activation of PKB/akt: involvement of MEK upstream of Bad phosphorylation. Proc Natl Acad Sci USA 1998, 95( I 3):7439-7444.

14. Zhang X, Odom DT, Koo SH, Conkright MD, Canettieri G, Best J, Chen $\mathrm{H}$, Jenner R, Herbolsheimer $\mathrm{E}$ and Jacobsen $\mathrm{E}$, et al: Genomewide analysis of cAMP-response element binding protein occupancy, phosphorylation, and target gene activation in human tissues. Proc Natl Acad Sci USA 2005, I 02(I 2):4459-4464.

15. Impey S, McCorkle SR, Cha-Molstad H, Dwyer JM, Yochum GS, Boss JM, McWeeney S, Dunn J], Mandel G and Goodman RH: Defining the CREB regulon: a genome-wide analysis of transcription factor regulatory regions. Cell 2004, I I 9(7): 104I-1054

16. Cheng IC Kinjo K Judelson D, Chang J. Wu WS, Schmid I, Shankar DB, Kasahara N, Stripecke R and Bhatia R, et al: CREB is a critical regulator of normal hematopoiesis and leukemogenesis. Blood 2007

17. Tuschl T: RNA interference and small interfering RNAs. Chembiochem 200I, 2(4):239-245.

18. Kim DH and Rossi J]: Strategies for silencing human disease using RNA interference. Nat Rev Genet 2007, 8(3):173-184.

19. Cheng JC and Sakamoto KM: The emerging role of RNA interference in the design of novel therapeutics in oncology. Cell Cycle 2004, 3(I I): I398-|40I.

20. Ventura A, Meissner A, Dillon C, McManus M, Sharp P, Paris L, Jaenisch $R$ and Jacks T: Cre-lox-regulated conditional RNA interference from transgenes. Proc Natl Acad Sci USA 2004, I 0 I (28): 10380-10385

21. Miyoshi H, Blomer U, Takahashi M, Gage FH and Verma IM: Development of a self-inactivating lentivirus vector. J Virol 1998, 72(10):8150-8157.

22. Su Al, Wiltshire $T$, Batalov $S$, Lapp $H$, Ching KA, Block $D$, Zhang J, Soden R, Hayakawa M and Kreiman G, et al: A gene atlas of the mouse and human protein-encoding transcriptomes. Proc Natl Acad Sci USA 2004, I 0 I ( I 6):6062-6067.

23. Fu WJ, Hu J, Spencer T, Carroll R and Wu G: Statistical models in assessing fold change of gene expression in real-time RTPCR experiments. Comput Biol Chem 2006, 30(I):2I-26.

24. Yuan JS, Reed A, Chen F and Stewart CN Jr: Statistical analysis of real-time PCR data. BMC Bioinformatics 2006, 7:85.

25. Liang $\mathrm{C}$, Feng $\mathrm{P}, \mathrm{Ku} \mathrm{B}$, Dotan I, Canaani D, Oh BH and Jung JU: Autophagic and tumour suppressor activity of a novel Beclin Ibinding protein UVRAG. Nat Cell Biol 2006, 8(7):688-699.

26. Liang XH, Jackson S, Seaman M, Brown K, Kempkes B, Hibshoosh H and Levine B: Induction of autophagy and inhibition of tumorigenesis by beclin I. Nature 1999, 402(6762):672-676.

27. Lyakhovich A and Shekhar MP: RAD6B overexpression confers chemoresistance: RAD6 expression during cell cycle and its redistribution to chromatin during DNA damage-induced response. Oncogene 2004, 23(I 7):3097-3106.

28. Shekhar MP, Lyakhovich A, Visscher DW, Heng $H$ and Kondrat $N$ : Rad6 overexpression induces multinucleation, centrosome amplification, abnormal mitosis, aneuploidy, and transformation. Cancer Res 2002, 62(7):2II5-2I24.

29. Cheng JC, Esparza S, Sandoval S, Shankar D, Fu C and Sakamoto KM: Potential role of CREB as a prognostic marker in acute myeloid leukemia. Future Oncol 2007, 3(4):475-480.

30. Chwang WB, Arthur JS, Schumacher A and Sweatt JD: The nuclear kinase mitogen- and stress-activated protein kinase I regulates hippocampal chromatin remodeling in memory formation. J Neurosci 2007, 27(46): |2732-12742.

31. Lehrmann H, Pritchard LL and Harel-Bellan A: Histone acetyltransferases and deacetylases in the control of cell proliferation and differentiation. Adv Cancer Res 2002, 86:4I-65.

\section{Pre-publication history}

The pre-publication history for this paper can be accessed here:

http://www.biomedcentral.com/1471-2407/8/264/ prepub 